\section{Strategies to Find Candidate Genes for Bipolar Disorder}

\author{
Sir.
}

Linkage studies have been revealing many new linkage loci not supporting previous regions of interest in the development of bipolar disorder. In addition, a number of association studies failed to get continuous replications as well as family based association studies in bipolar disorders. ${ }^{1}$ Moreover, 5-HTTLPR and brain-derived neurotrophic factor (BDNF) promoter polymorphisms are now found to be more complex than previously thought, and thus previous papers on these polymorphisms should be treated with caution, although some researchers picked these genes as relatively most promising candidates for bipolar disorder. ${ }^{1,2}$

As proposed before, we could have more well-organized and robust information by interactive approaches combining multiple candidate genes, contributing psychosocial factors and establishment of potential endophenotypes for bipolar disorder. However, these new approaches would be liable to a repetition of trial and error as did past studies since such individual approach has its inherent pitfalls (i.e., complexity of polymorphisms, for example, 5-HTTLPR was found to have novel alleles showing different functional significance; syndromal diagnosis of bipolar disorder; presence of small effect genes)., ${ }^{2,3}$

Hence we need more clearly-defined new pathway to find candidate genes, for example, setup of worldwide cooperation, consensus and protocols for genetic studies which may be lessoned from practical clinical trials, i.e., CATIE $^{4}$ and EUFEST ${ }^{5}$ studies. In fact we may focus on more highly selective diseased family data with this approach, i.e., focusing on single large family excluding geographic and genetic heterogeneity.

We may also need to quantify the role of candidate genes after complete interactive analyses for their contribution to the disorder and then weighted values should be given as their rates of contribution, which eventually might give us a statistically stringent model incorporating proven potential genes (i.e., namely targeted candidate gene cluster level I, II and III etc.).

Other option might be a combination of phylogenetic and endophenotypic approach to bipolar disorder since the disorder has different clinical and biological faces, although currently bipolar disorders are simply categorized as same phenomenological classification and genetic studies are also based on simple diagnostic criteria. Finally well-organized and systematized pathway-based candidate gene analysis not searching individual gene analysis based on specific pathophysiology will also help us to shorten finding high risk genes.

Definitely today is just preparing the first puzzle but not finding the final one. I believe that the efficient strategies and tactics to find precise implications through stepwise integration of currently available findings are more important than finding a new candidate gene today.

\section{- Acknowledgments}

This work was supported by a grant from the Medical Research Center, Korea Science and Engineering Foundation, Republic of Korea (R13-2002-005-04001-0).

\section{REFERENCES}

1) Serretti A, Mandelli L. The genetics of bipolar disorder: genome 'hot regions', genes, new potential candidates and future directions. Mol Psychiatry 2008;13:742-771.

2) Kato T. Molecular genetics of bipolar disorder. Neurosci Res 2001; 40:105-113.

3) Izumi A, Iijima Y, Noguchi H, Numakawa T, Okada T, Hori H, et al. Genetic variations of human neuropsin gene and psychiatric disorders: polymorphism screening and possible association with bipolar disorder and cognitive functions. Neuropsychopharmacology 2008;33: 3237-3245.

4) Lieberman JA, Hsiao JK. Interpreting the results of the CATIE study. Psychiatr Serv 2006;57:139.

5) Fleischhacker WW, Keet IP, Kahn RS. The European First Episode Schizophrenia Trial (EUFEST): rationale and design of the trial. Schizophr Res 2005;78:147-156.

Chi-Un Pae, MD, PhD

Department of Psychiatry, Holy Family Hospital, The Catholic University of Korea College of Medicine,

2 Sosa-dong, Wonmi-gu, Bucheon 420-717, Korea Tel: 82-32-340-0675, Fax: 82-2-6442-2789

E-mail: pae@catholic.ac.kr

Department of Psychiatry and Behavioral Sciences, Duke University Medical Center, 2218 Elder St., Durham 27705, NC, USA

\footnotetext{
c) This is an Open Access article distributed under the terms of the Creative Commons Attribution Non-Commercial License (http://creativecommons.org/ licenses/by-nc/3.0) which permits unrestricted non-commercial use, distribution, and reproduction in any medium, provided the original work is properly cited.
} 